prescription, the number of phone calls made by pharmacists to physicians and the number of changes made after these phone calls. Results In 2011, prescriptions were re-evaluated in 69\% of the cases, with a statistically significant increase $(p<0.01)$ between 2010 and 2011. Compliance with the AR was $75 \%$, CR was $86 \%$, the PR was $72 \%$ and the relevance of the prescription reached $70 \%$. Compliance with these last criteria increased in 2010, but decreased again in $2011.15 \%$ of the prescriptions required a phone call, of which $47 \%$ were followed by a change in the prescription.

Conclusions The continuation of ATB treatment requires reevaluation according to the antibiogram or the clinical evolution. The improvements achieved in 2010 in prescription conformity and in the proper use of ATBs as last resort can be attributed to the distribution of the guide to proper use of anti-infectious drugs and changes in the presentation of prescriptions. Nevertheless, the significant decrease in 2011 requires physicians who are prolific prescribers to be sensitised. The active involvement of pharmacists in the anti-infectious drugs committee contributes to promoting the proper use of ATBs. Pharmacists called less than last year but their phone calls were more targeted and relevant.

No conflict of interest.

\section{DGI-008 ANALYSIS OF THE USE OF CARBOXYMALTOSE IRON IN A UNIVERSITY HOSPITAL}

doi:10.1136/ejhpharm-2013-000276.274

B Escudero-Vilaplana, C Folguera-Olias, A Díaz-Alcántara, V Saavedra-Quirós, A MartínAlonso, A Torralba-Arranz. Hospital Universitario Puerta de Hierro, Pharmacy, Madrid, Spain

Background Recently the use of IV carboxymaltose iron at doses of 500-1000 mg has increased in our hospital, even though it is not included in the formulary and it should be only used to avoid blood transfusions.

Purpose To evaluate the use of carboxymaltose iron in a university hospital.

Materials and Methods A longitudinal, descriptive study was carried out in patients treated with iron carboxymaltose from January 2011 to June 2012 in a university hospital. Data was collected from special orders of non-formulary drugs. Variables recorded: sex, age, prescribing service, indication, haemoglobin $(\mathrm{Hb})$ prior to and after the administration of iron, dose of iron and number of administrations in each patient. Safety was also considered by analysing any adverse effects (AEs) reported to the Pharmacy Department.

Results 85 patients were included (60.0\% female; median age 50.1 [SD:19.2]). Prescribing services were: Gynaecology and Obstetrics (30.6\%), Haematology (29.4\%), Nephrology (17.6\%), Digestive $(12.9 \%)$ and others $(9.5 \%)$. Main indications were: anaemia secondary to chronic kidney disease (CKD) $(20.0 \%)$, postpartum anaemia $(17.6 \%)$, undetermined anaemia (14.1\%), iron deficiency anaemia $(12.9 \%)$, gastrointestinal bleeding $(8.2 \%)$, post-surgical anaemia $(8.2 \%)$, pre-surgical anaemia $(5.9 \%)$, others $(10.7 \%)$ and unspecified indication $(2.4 \%)$. Mean $\mathrm{Hb}$ prior to the iron administration was $9.5(\mathrm{SD}=2.0) \mathrm{g} / \mathrm{dl}$ and $11.5(\mathrm{SD}=1.7) \mathrm{g} / \mathrm{dl}$ after the treatment. Mean dose of carboxymaltose iron used was $754 \mathrm{mg}(\mathrm{SD}=251) \mathrm{mg}$. $71.8 \%$ patients received a single iron dose during the study period, $14.1 \%$ received two administrations, $5.9 \%$ received three administrations and $8.3 \%$ received four or more administrations. No AEs associated with the drug were reported to the Pharmacy Department.

Conclusions The main uses of carboxymaltose iron were anaemia secondary to $\mathrm{CKD}$ and postpartum anaemia. A third of the prescriptions corresponded to surgical patients. However, $16.5 \%$ orders specified neither the indication nor the type of anaemia. Our data has shown effectiveness and safety in the use of carboxymaltose iron.

No conflict of interest.

\section{DGI-009 ANALYSIS OF THE USE OF ERYTHROPOIESIS-STIMULATING AGENTS IN A UNIVERSITY HOSPITAL}

doi:10.1136/ejhpharm-2013-000276.275

'V Escudero-Vilaplana, ${ }^{2} \mathrm{~A}$ Vega-Martínez, ${ }^{2} \mathrm{JM}$ López-Gómez, 'CG Rodríguez-Gónzalez, 'B Marzal-Alfaro, 'P Arrabal-Durán, 'R Romero-Jiménez, 'A Giménez-Manzorro, II Marquínez-Alonso, 'M Sanjurjo-Sáez. 'Hospital General Universitario Gregorio

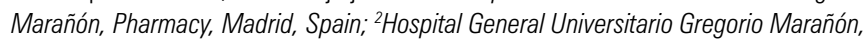
Nephrology, Madrid, Spain

Background The use of erythropoiesis-stimulating agents (ESA) in the treatment of anaemia due to chronic kidney disease (CKD) is highly variable regarding patient characteristics and doses, including the equivalence among ESAs stated in the label product.

Purpose To evaluate the use of ESAs for anaemia due to CKD in a university hospital.

Materials and Methods A descriptive, transversal study was performed in patients treated with ESAs for anaemia secondary to $\mathrm{CKD}$ in a university hospital over a month. The principle variable was monthly dose of ESA. Secondary aims were to assess: efficacy (defined in terms of haemoglobin levels $[\mathrm{Hb}]$ ) and safety (defined in terms of percentage of patients with $\mathrm{Hb}>13 \mathrm{~g} / \mathrm{dl}$ ). Variables collected were: demographic characteristics, ESA type and dose, prescribing Service, $\mathrm{Hb}$, serum creatinine $(\mathrm{Cr})$, C-reactive protein, albumin, ferritin, transferrin saturation index, folate, vitamin B12 and parathyroid hormone (PTH).

Results 333 patients were included $(52.6 \%$ female; median age 75.2 years). $69.1 \%$ patients were on pre-dialysis, $27.6 \%$ on haemodialysis and $3.3 \%$ on peritoneal dialysis. The prescription profile was: $23.4 \%$ epoetin, $41.4 \%$ darbepoetin $\alpha$ and $35.1 \%$ CERA. $97.0 \%$ prescriptions from Nephrology Service. Median [p25, p75] dose/month was: epoetin $(12857$ [8571, 25714] IU), darbepoetin $\alpha(86[43,129]$ mcg), CERA (75 [50, 100] mcg). Hb levels: epoetin (11.9 [11.3, 12.5] $\mathrm{g} / \mathrm{dl})$, darbepoetin $\alpha(11.9[11.1,12.8] \mathrm{g} / \mathrm{dl})$, CERA $(12.1[11.0,12.8]$ $\mathrm{g} / \mathrm{dl}) ; \mathrm{p}=0.860$. Patients with $\mathrm{Hb}>13 \mathrm{~g} / \mathrm{dl}: 11.5 \%$ epoetin, $19.6 \%$ darbepoetin $\alpha, 22.2 \%$ CERA; $p=0.639$. Patients treated with CERA had more favourable levels of $\mathrm{Cr}$, albumin and PTH than those treated with epoetin and darbepoetin $\alpha(p<0.05)$.

Conclusions Efficacy and safety were similar for different types of ESAs. CERA dose was lower than the recommended equivalence stated in the label product for the doses of epoetin and darbepoetin $\alpha$ obtained, although patients treated with CERA had a better kidney function.

No conflict of interest.

\section{DGI-010 ANALYSIS OF THE USE OF FINGOLIMOD IN PATIENTS WITH MULTIPLE SCLEROSIS IN A UNIVERSITY HOSPITAL}

doi:10.1136/ejhpharm-2013-000276.276

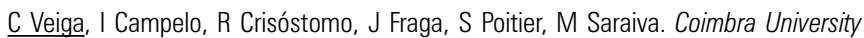
Hospital, Pharmacy, Coimbra, Portugal

Background Multiple Sclerosis (MS) is a chronic, inflammatory and degenerative disease, which affects the Central Nervous System [1]

Fingolimod (FTY) is a medicine indicated in the treatment of MS patients with active exacerbation/remitting episodes. Being an expensive, innovative treatment it has been the subject of careful monitoring.

Purpose To evaluate the use of FTY between May 2011 and September 2012. To evaluate the benefits in reducing disease progression.

Materials and Methods Retrospective analysis of FTY use in MS patients in outpatient care, followed in Demyelinating Diseases Consultation. The number of outbreaks and Kurtzke Expanded Disability Status Scale (EDSS) scores, blood pressure and heart rate were examined using a pharmacy database and patients' medical records. 
Results Twenty six patients were investigated:

- Previous treatment: 10 patients with natalizumab (4 for over 2 years), 8 with interferon beta (IFN $\beta$ ) (6 of them for more than 1 year), 3 with glatiramer acetate (GA), 3 with azathioprine with mycophenolate mofetil and 1 with methotrexate.

- FTY treatment periods: 4 patients had started $<1$ month ago; 18 between 1-6 months; 3 between $6-12$ months and one $>1$ year.

- Vital parameters: mean arterial pressure (MAP): 121.29 $\mathrm{mmHg} / 70.41 \mathrm{mmHg}$ and $113.06 \mathrm{mmHg} / 68.31 \mathrm{mmHg}$ after $6 \mathrm{~h}$ of administration. The mean heart rate (MHR): 71.06 beats/min and 62.53 beats/min after $6 \mathrm{~h}$

- Disease progression: 1 patient suffered only one flare-up. Nine patients had a mean decrease of 0.72 in the EDSS scale and 4 maintained the values. There was no increase in lesion extension in Nuclear Magnetic Resonance.

- Average monthly costs: FTY $€ 1,872.5$; INF $\beta / G A$ (1st line) $€ 843.91$; natalizumab $€ 1,923.90$ (costs related to the route of administration were not counted).

Conclusions There was no worsening of symptoms after introduction of FTY and there was only one recrudescence episode, requiring long-term assessment.

Despite costing more than first-line medicines, FTY was the best option because it is an oral formulation, so is more convenient for patients.

\section{Reference}

1. Portuguese Society of Multiple Sclerosis

No conflict of interest.

\section{DGI-011 ANTI-TUMOR NECROSIS FACTOR REAL-WORLD DOSES: FOUR-YEAR RETROSPECTIVE STUDY IN RHEUMATOID ARTHRITIS PATIENTS IN TWO HOSPITALS IN SPAIN}

doi:10.1136/ejhpharm-2013-000276.277

'E Alañón, ${ }^{2} \mathrm{~V}$ Escudero, ${ }^{1} E$ Ramírez, ${ }^{2} \mathrm{~N}$ Trovato, ${ }^{2} \mathrm{MJ}$ Bellin, ${ }^{1} \mathrm{~A}$ Morell, ${ }^{2} \mathrm{M}$ Sanjurjo. ${ }^{1}$ Hospital Universitario De La Princesa, Pharmacy Department, Madrid, Spain; ${ }^{2}$ Hospital General Universitario Gregorio Marañón, Pharmacy Department, Madrid, Spain

Background Achieving minimum clinically effective doses offers major advantages in safety and efficiency.

Purpose To evaluate mean dosage in rheumatoid arthritis (RA) patients treated with adalimumab (ADA), etanercept (ETN) and infliximab (IFX). To correlate these dose strategies with the patient's disease activity. To estimate annual costs associated.

Materials and Methods Observational, retrospective study. RA patients who received ADA, ETN or IFX for at least 6 months during 2006-2010 were included. Patients could receive different sequential treatments. Mean drug consumption was analysed based on hospital pharmacy service claims and presented as a percentage of the standard RA dose. Escalated and reduced doses were defined as those higher and lower than standard doses. Demographic data, concomitant treatment, disease activity (DAS28ESR) and antiTNF dosage were analysed. The therapeutic objective was defined as DAS28 < 3.2. Associated annual costs were estimated based on public ex-factory prices including tax (2011 Euros).

Results 198 patients (mean age 60.5 years $[ \pm 13.06]$, 80\% female, baseline DAS28 $=4.38[ \pm 1.52]$ ). 215 cases: ADA ( 66 first line, 7 second line), ETN (71 first line, 9 second line, 1 third line), IFX (61 first line).

Conclusions There were no statistical differences regarding baseline disease activity $(p>0.05)$. Patients in the ADA or IFX groups increased doses above standard doses more frequently than ETN patients $(\mathrm{p}<0.05)$.

There were no differences between groups in percentage of patients with DAS28 $<3.2(\mathrm{P}=0.927)$.

AntiTNF real-world data shows significant differences compared to recommended doses, which directly affect treatment costs and efficiency. Measuring efficiency in clinical practise is key for optimization and rational use of biological medicines.

Abstract DGI-011 Table 1

\begin{tabular}{|c|c|c|c|}
\hline & $\begin{array}{l}\text { ADA } \\
N=73\end{array}$ & $\begin{array}{l}\text { ETN } \\
N=81\end{array}$ & $\begin{array}{l}\text { IFX* } \\
N=61\end{array}$ \\
\hline Concomitant DMARDs (\%) & $80.83 \%$ & $74.07 \%$ & $90.16 \%$ \\
\hline Study real doses ${ }^{\dagger}$ & $\begin{array}{l}93.02 \%^{\dagger} \\
(37.21 \mathrm{mg} / \mathrm{biw})\end{array}$ & $\begin{array}{l}81.00 \%{ }^{\dagger} \\
\text { (40.5 mg/week) }\end{array}$ & $\begin{array}{l}135.73 \%^{\dagger} \\
\text { (4.07 mg/kg/8 weeks) }\end{array}$ \\
\hline Mean reduced doses & $32.88 \%$ & $46.91 \%$ & $8.2 \%$ \\
\hline Mean increased doses & $9.58 \%$ & $3.7 \%$ & $75.41 \%$ \\
\hline DAS28 < $3.2(\%)$ & $67.12 \%$ & $65.43 \%$ & $62.30 \%$ \\
\hline Patient-year cost (standard doses) & $12,859.79 €$ & $11,845.93 €$ & $7,566.27 €$ \\
\hline Patient-year cost (clinical practise) $)^{\star}$ & $11,962.58 €^{*}$ & $9,594.73 €$ & $10,094.53 €$ \\
\hline Patient-year cost differences ${ }^{\dagger}$ & $-897.22 €^{\dagger}$ & $-2,251.20 €^{\dagger}$ & $+2,528.26 €^{\dagger}$ \\
\hline
\end{tabular}

${ }^{*}$ IFX: $110.93 € /$ infusion, $0.89 \%$ waste optimising vials. Mean weight: $68.04 \mathrm{~kg}$.

ip $<0.05$ between groups

$\$$ : $<0.05$ ADA vs. ETN, ADA vs. INF

No conflict of interest.

\section{DGI-012 ANTIBIOTICS MONITORING: THE EXPERIENCE OF LIGURIA REGION, ITALY}

doi:10.1136/ejhpharm-2013-000276.278

${ }^{1} \mathrm{C}$ Nurchis, ${ }^{1} \mathrm{~T}$ Chiarello, ${ }^{1} \mathrm{C}$ Bianchi, ${ }^{2} \mathrm{E}$ Ferelli, ${ }^{3} \mathrm{~F}$ Morotti, ${ }^{3} \mathrm{~S}$ Gamba, ${ }^{3} \mathrm{~L}$ Riceputi, ${ }^{4} \mathrm{~A}$ Brega, ${ }^{4} \mathrm{~F}$ Trovato, ${ }^{5} \mathrm{~S}$ Zuccarelli, ${ }^{6} \mathrm{~S}$ Borgna, ${ }^{7} \mathrm{~S}$ Peri. ' Villa Scassi Hospital, Dipartimento Attività Farmaceutiche, Genova, Italy; ${ }^{2}$ Galliera Hospital, S.C. Farmacia, Genova, Italy; ${ }^{3}$ rrccs Gaslini, S.C. Farmacia, Genova, Italy; ${ }^{4}$ rccs San-Martino-Ist, S.C. Farmacia, Genova, Italy; ${ }^{5}$ Sspedale As/3, Dipartimento Attività Farmaceutiche, Genova, Italy; ${ }^{6}$ Farmaceutica Territoriale As/3, Dipartimento Attività Farmaceutiche, Genova, Italy; ${ }^{\top} A s / 4$ Chiavarese, S.C. Farmaceutica Ospedaliera, Genova, Italy

Background The Health Department of Regione Liguria has introduced the obligation, for every hospital department to motivate the request to obtain certain kinds of antibiotics, because their use is restricted to serious infections and in consideration of their high cost.

Purpose The aim is to restrict the phenomenon of resistance to antibiotics and reduce the rising consumption of these drugs, guaranteeing a correct prescription.

Materials and Methods The request for the drugs in question must be made using the appropriate form containing the clinical data of the patients, including personal details, diagnosis and the characteristics of the infection.

The pharmacist verifies the administration dosage and the conformity of the diagnosis with the approved health authority indications and with prophylaxis guidelines. The pharmacist will then decide whether to dispense the drug.

Some hospitals make use of written applications, others have created specific software for this purpose, others have included the application in the software for the management of the hospital admissions and patients records. Furthermore, where necessary, it has been possible also to include specialist advice, in the software.

Results In the 2011 the Local Health Board of Genoa (ASL3) received and monitored 2274 specific forms, that is $100 \%$ of the requests. The intervention of the pharmacist led to a reduction of $90 \%$ in the use of Tigecycline and prevented, in 31 cases, an overdose of Vancomycin hydrochloride on Clostridium Difficile Infection. Administration of oral vancomycin in Clostridium difficile infection was $500 \mathrm{mg}$ qid orally for at least 10 days instead of $125 \mathrm{mg}$ qid orally stated in the international guidelines.

The control of reasoned request by the pharmacist allowed to use the appropriate dosage.

In the Galliera Hospital, 2100 specific forms were filled out (70\% of the total requests). Antibiotics non requiring a specific request like ciprofloxacin, ceftriaxone, ceftazidime were used more than in 2009. (2009: 20872units; 2011:25508 units) 